\title{
The short-term association between asthma hospitalisations, ambient temperature, other meteorological factors and air pollutants in Hong Kong: a time-series study
}

\author{
Holly Ching-yu Lam, ${ }^{1}$ Albert Martin Li, ${ }^{2}$ Emily Ying-yang Chan, ${ }^{1}$ \\ William Bernard Goggins III
}

${ }^{1}$ The Jockey Club School of Public Health and Primary Care, The Chinese University of Hong Kong, Shatin, Hong Kong SAR

${ }^{2}$ Department of Paediatrics, The Chinese University of Hong Kong, Shatin, Hong Kong SAR

\section{Correspondence to} William B Goggins III, The Jockey Club School of Public Health and Primary Care (CUHK), Prince of Wales Hospital, Shatin, Hong Kong SAR; wgoggins@cuhk.edu.hk

Received 12 November 2015 Revised 20 May 2016 Accepted 6 June 2016 Published Online First 24 June 2016

\section{SLinked}

- http://dx.doi.org/10.1136/ thoraxjnl-2016-209009

\section{CrossMark}

\footnotetext{
To cite: Lam HC-yu, Li AM, Chan EY-yang, et al. Thorax 2016;71:1097-1109.
}

\begin{abstract}
Background Previous studies have found associations between meteorological variables and asthma

hospitalisations but the nature of these associations has varied and few studies have been done in subtropical areas or evaluated effect modification by age. Objectives This study aimed to evaluate associations between asthma hospitalisations and meteorological factors and to assess effect modification of these associations by age and season in Hong Kong. Methods Poisson generalised additive models combined with distributed lag nonlinear models and piecewise linear models were used to model associations between daily asthma hospitalisations from 2004 to 2011 and meteorological factors and air pollutants, adjusting for day of week, seasonality and trend. Subgroup analyses by age and season were performed.

Results In the hot season, hospitalisations were lowest at $27^{\circ} \mathrm{C}$, rose to a peak at $30^{\circ} \mathrm{C}$, then plateaued between $30^{\circ} \mathrm{C}$ and $32^{\circ} \mathrm{C}$. The cumulative relative risk for lags $0-3$ days (RRlag0-3) for $30^{\circ} \mathrm{C}$ vs $27^{\circ} \mathrm{C}$ was 1.19 (95\% Cl 1.06 to 1.34). In the cold season, temperature was negatively associated with asthma hospitalisations. The cumulative RRlag0-3 for $12^{\circ} \mathrm{C}$ vs $25^{\circ} \mathrm{C}$ was 1.33 (95\% Cl 1.13 to 1.58). Adult admissions were most sensitive to temperatures in both seasons while admissions among children under 5 were least

\section{Key messages}

What is the key question?

- What sort of associations exist between asthma hospitalisations and meteorological and environmental parameters in a densely populated Asian city with a subtropical climate?

\section{What is the bottom line?}

- More asthma hospitalisations were associated with high temperatures, relative humidity and ozone levels in the hot season and low temperatures and relative humidity in the cool season.

\section{Why read on?}

- This study, which used advanced statistical models that allow for the nonlinear and lagged association and had a very large sample size which allowed subgroup analyses to be performed, found that asthma admissions showed considerably different sensitivities to meteorological and environmental conditions between children, adults and the elderly.
\end{abstract} associated. Higher humidity and ozone levels in the hot season, and low humidity in the cold season were also associated with more asthma admissions.

Conclusions People with asthma should avoid exposure to adverse conditions by limiting outdoor activities during periods of extreme temperatures, combinations of high humidity and high temperature, and low humidity and low temperature, and high ozone levels.

\section{INTRODUCTION}

According to WHO, asthma is among the most common chronic respiratory diseases and there are currently over 235 million people with the disease worldwide. ${ }^{1}$ Asthma is characterised by chronic airway inflammation and high sensitivity to various triggers. Once triggered the inflamed airway swells further, the muscle of the airway wall tightens, and extra mucus is secreted, leading to the common symptoms of asthma, including coughing, wheezing, shortness of breath and chest tightness. Although the fundamental causes of asthma are still unclear, some factors that trigger asthma have been identified, including environmental factors, such as pollens, pollutants and tobacco smoke, and chemical irritants at the workplace, host factors, such as respiratory infections, and psychological factors, such as fear and anger. ${ }^{1}$ Asthma cannot be cured but can be controlled by medicines and by avoiding exposure to risk factors.

Previous studies have assessed the environmental risk factors for asthma and some have reported that high and low ambient temperatures were associated with higher asthma morbidity. ${ }^{2-10}$ However, the nature of these associations varied across studies in different geographic locations, likely due to differences in climate, socioeconomic development, and genetic characteristics. A study from Australia ${ }^{6}$ reported a positive association between childhood asthma morbidity and temperature, while a study 
Table 1 Descriptive statistics of daily number of asthma admissions, meteorological factors and air pollutants in Hong Kong during 2004-2011

\begin{tabular}{|c|c|c|c|c|c|c|c|c|}
\hline & Min. & $\begin{array}{l}\text { 3rd } \\
\text { percentile }\end{array}$ & $\begin{array}{l}\text { 25th } \\
\text { percentile }\end{array}$ & Median & Mean & $\begin{array}{l}\text { 75th } \\
\text { percentile }\end{array}$ & $\begin{array}{l}\text { 97th } \\
\text { percentile }\end{array}$ & Max. \\
\hline \multicolumn{9}{|l|}{ Whole year } \\
\hline Daily no. of asthma admissions & 5.00 & 9.00 & 15.00 & 19.00 & 19.20 & 23.00 & 32.00 & 46.00 \\
\hline Mean temperature $\left({ }^{\circ} \mathrm{C}\right)$ & 8.80 & 12.70 & 19.30 & 24.60 & 23.36 & 27.80 & 30.03 & 31.80 \\
\hline Mean RH (\%) & 31.00 & 53.00 & 73.00 & 79.00 & 77.94 & 85.00 & 94.00 & 98.00 \\
\hline Solar radiation $\left(\mathrm{MJ} / \mathrm{m}^{2}\right)$ & 0.64 & 2.44 & 8.34 & 13.97 & 13.51 & 18.05 & 25.58 & 28.81 \\
\hline Wind speed $(\mathrm{km} / \mathrm{h})$ & 3.00 & 6.80 & 15.10 & 21.90 & 22.47 & 28.60 & 42.73 & 70.00 \\
\hline $\mathrm{PM}_{10}\left(\mu \mathrm{g} / \mathrm{m}^{3}\right)$ & 9.75 & 18.90 & 31.25 & 49.44 & 53.79 & 71.23 & 109.36 & 586.40 \\
\hline $\mathrm{SO}_{2}\left(\mu \mathrm{g} / \mathrm{m}^{3}\right)$ & 3.70 & 5.79 & 10.76 & 15.85 & 18.68 & 22.83 & 48.77 & 113.97 \\
\hline $\mathrm{NO}_{2}\left(\mu \mathrm{g} / \mathrm{m}^{3}\right)$ & 14.41 & 27.31 & 46.51 & 59.61 & 62.15 & 75.18 & 110.23 & 180.07 \\
\hline $\mathrm{O}_{3}\left(\mu \mathrm{g} / \mathrm{m}^{3}\right)$ & 6.17 & 11.07 & 18.98 & 32.97 & 36.23 & 49.37 & 78.20 & 122.12 \\
\hline \multicolumn{9}{|l|}{ Hot seasons } \\
\hline Daily no. of asthma admissions & 5.00 & 8.00 & 14.00 & 17.00 & 17.45 & 21.00 & 29.00 & 40.00 \\
\hline Mean temperature $\left({ }^{\circ} \mathrm{C}\right)$ & 18.70 & 23.60 & 26.10 & 27.80 & 27.52 & 29.10 & 30.40 & 31.80 \\
\hline Mean RH (\%) & 45.00 & 62.00 & 75.00 & 80.00 & 79.88 & 85.00 & 94.00 & 98.00 \\
\hline Solar radiation $\left(\mathrm{MJ} / \mathrm{m}^{2}\right)$ & 0.73 & 3.18 & 10.40 & 16.18 & 15.54 & 20.79 & 26.68 & 28.81 \\
\hline Wind speed $(\mathrm{km} / \mathrm{h})$ & 3.20 & 6.70 & 13.50 & 19.35 & 21.07 & 27.00 & 44.58 & 70.00 \\
\hline $\mathrm{PM}_{10}\left(\mu \mathrm{g} / \mathrm{m}^{3}\right)$ & 14.42 & 17.75 & 24.86 & 34.36 & 43.33 & 56.18 & 102.45 & 154.08 \\
\hline $\mathrm{SO}_{2}\left(\mu \mathrm{g} / \mathrm{m}^{3}\right)$ & 3.87 & 5.61 & 10.08 & 15.43 & 18.86 & 22.96 & 55.24 & 113.97 \\
\hline $\mathrm{NO}_{2}\left(\mu \mathrm{g} / \mathrm{m}^{3}\right)$ & 14.41 & 24.97 & 38.80 & 50.76 & 54.23 & 65.83 & 100.67 & 142.10 \\
\hline $\mathrm{O}_{3}\left(\mu \mathrm{g} / \mathrm{m}^{3}\right)$ & 6.17 & 11.34 & 17.37 & 25.99 & 34.43 & 49.12 & 79.50 & 120.87 \\
\hline \multicolumn{9}{|l|}{ Cold seasons } \\
\hline Daily no. of asthma admissions & 7.00 & 11.00 & 16.00 & 20.00 & 20.98 & 25.00 & 34.00 & 46.00 \\
\hline Mean temperature $\left({ }^{\circ} \mathrm{C}\right)$ & 8.80 & 11.70 & 16.70 & 19.30 & 19.15 & 21.80 & 25.85 & 27.80 \\
\hline Mean RH (\%) & 31.00 & 48.00 & 69.00 & 78.00 & 75.97 & 85.00 & 94.00 & 97.00 \\
\hline Solar radiation $\left(\mathrm{MJ} / \mathrm{m}^{2}\right)$ & 0.64 & 2.13 & 6.74 & 12.31 & 11.45 & 15.74 & 21.02 & 27.70 \\
\hline Wind speed $(\mathrm{km} / \mathrm{h})$ & 3.00 & 7.50 & 17.60 & 23.80 & 23.89 & 29.80 & 41.89 & 60.70 \\
\hline $\mathrm{PM}_{10}\left(\mu \mathrm{g} / \mathrm{m}^{3}\right)$ & 9.75 & 26.21 & 45.16 & 60.92 & 64.40 & 78.79 & 117.69 & 586.40 \\
\hline $\mathrm{SO}_{2}\left(\mu \mathrm{g} / \mathrm{m}^{3}\right)$ & 3.70 & 6.51 & 11.41 & 16.11 & 18.49 & 22.76 & 42.42 & 107.46 \\
\hline $\mathrm{NO}_{2}\left(\mu \mathrm{g} / \mathrm{m}^{3}\right)$ & 25.34 & 40.62 & 55.52 & 67.10 & 70.20 & 80.89 & 117.71 & 180.07 \\
\hline $\mathrm{O}_{3}\left(\mu \mathrm{g} / \mathrm{m}^{3}\right)$ & 6.37 & 10.69 & 23.62 & 36.85 & 38.06 & 49.46 & 76.50 & 122.12 \\
\hline
\end{tabular}

$\mathrm{RH}$, relative humidity.

from Shanghai ${ }^{2}$ reported higher numbers of admissions during periods of low temperature. In Hong Kong, large diurnal temperature ranges were found to be associated with more emergency hospital admissions for asthma. ${ }^{11}$ However, the associations between daily mean temperatures, other meteorological factors, and asthma hospitalisations in Hong Kong were not reported in that study, ${ }^{11}$ and have not been reported in any other studies to date. Thermoregulation ability, comorbidity prevalence, lung function, responsiveness to rescue medicines and disease severity are different among children, adults and the elderly. ${ }^{12-15}$ Thus age is a possible effect modifier of the asthma-temperature association. Several studies have reported on associations in different age groups. ${ }^{5816}$ However, only one study from Korea compared associations among children, adults and the elderly from the same population, ${ }^{5}$ and reported a higher risk for children under 15 than for adults or the elderly at low temperatures, but did not report on differences between age groups for other environmental variables. Other studies have only compared the associations between either children and adults, ${ }^{16}$ or the elderly and non-elderly. ${ }^{8}$

Understanding the association between asthma hospitalisations and ambient temperature, and how the associations vary across age groups, is important in developing strategic health protection policies. In this study, associations between asthma hospitalisations and ambient temperatures and other environmental factors in Hong Kong, a densely populated city with a subtropical climate, were assessed using a time-series approach. In addition, subgroup analyses by age group and season were done to assess potential effect modification by these variables.

\section{METHODS \\ Data}

Data on all public hospital admissions in Hong Kong during the period 2004-2011, including age, gender and International Classification of Diseases code (ICD-9) for principal diagnosis at discharge, were obtained from the Hospital Authority. Admission records with principal diagnosis at discharge code ICD-9 493.xx were included in the study. Meteorological data including daily mean temperature $\left({ }^{\circ} \mathrm{C}\right)$, daily mean relative humidity percentage $(\mathrm{RH} \%)$, daily mean solar radiation $\left(\mathrm{MJ} / \mathrm{m}^{2}\right)$, daily mean wind speed $(\mathrm{km} / \mathrm{h})$ and daily rainfall $(\mathrm{mm})$ were obtained for a single central monitoring station from the Hong Kong Observatory (HKO). Air pollutant data including average daily level of respirable suspended particulates (RSP/PM 10 in $\mu \mathrm{g} / \mathrm{m}^{3}$ ), average daily level of sulphur dioxide $\left(\mathrm{SO}_{2}\right.$ in $\left.\mu \mathrm{g} / \mathrm{m}^{3}\right)$, nitrogen dioxide $\left(\mathrm{NO}_{2}\right.$ in $\left.\mu \mathrm{g} / \mathrm{m}^{3}\right)$ and ozone $\left(\mathrm{O}_{3}\right.$ in $\left.\mu \mathrm{g} / \mathrm{m}^{3}\right)$ were collected from 11 general stations and 3 roadside stations of the Hong Kong Environmental Protection Department. Data from Tap Mun station, a remote area with small population, and from the roadside stations, were excluded as these data might not represent the exposure of the overall population. Data from the remaining 10 general stations, which are widely spread throughout the city and 

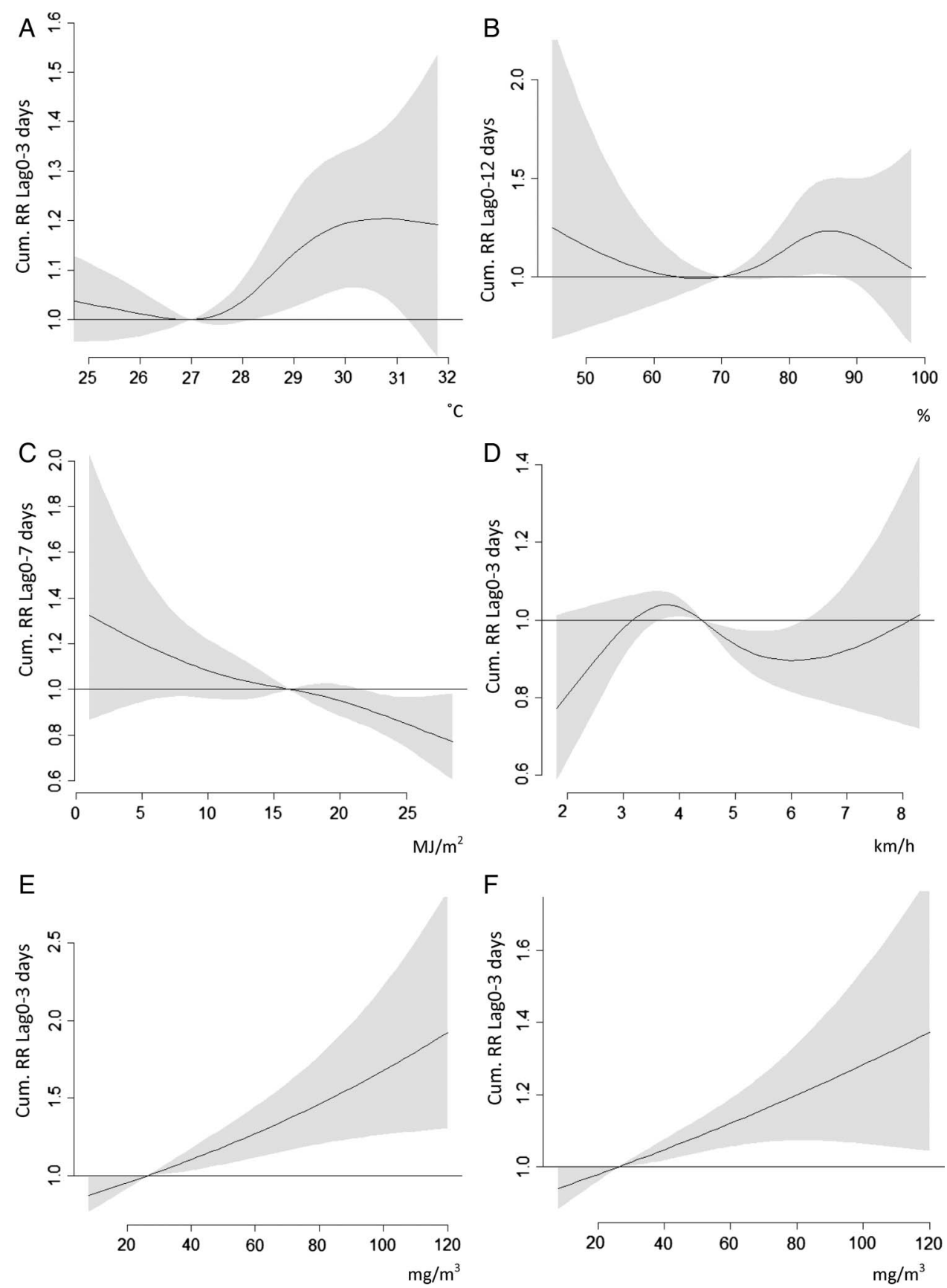

Figure 1 Plots of cumulative relative risks (cum. RR) during the hot season (May-October, 2004-2011, Hong Kong) in overall population against: (A) mean temperature, (B) relative humidity, (C) solar radiation, (D) square-root-transformed wind speed, (E) ozone in single-pollutant model and (F) ozone in multi-pollutant model.

are located in districts with a large population, were averaged to produce the daily values for each pollutant.

\section{Statistical models}

A combination of Poisson generalised additive models (GAMs) ${ }^{17}$ and distributed lag nonlinear models (DLNMs) ${ }^{18}$ was used to assess the potentially nonlinear association between meteorological and pollutant variables and asthma hospitalisations allowing for lagged effects. The model was as below:

$\log (\mathrm{E}[$ daily number of ASTHMA admissions $])=$

cb(temperature, $\mathrm{df}=4$; lag, $\mathrm{df}=4)+\mathrm{cb}(\mathrm{RH}, \mathrm{df}=3$; lag, $\mathrm{df}=4)$ $+\mathrm{cb}$ (sqrt.wind speed, $\mathrm{df}=3$; lag, $\mathrm{df}=4)+\mathrm{cb}($ solar radiation, $\mathrm{df}=3$; lag, $\mathrm{df}=4)+\mathrm{cb}($ air pollutants, $\mathrm{df}=2$; lag, $\mathrm{df}=4)+\mathrm{cb}($ influenza, $\mathrm{df}=2$; lag, $\mathrm{df}=4)+\mathrm{cb}(\mathrm{ARI}, \mathrm{df}=2 ; \mathrm{lag}, \mathrm{df}=4)+\mathrm{s}($ sqrt.rain, $k=3)+s($ DOS,$\quad k=7)+s($ DOY,$\quad k=5)+$ factor $(D O W)+$ factor (holiday)

cb: cross basis of independent variables built up using the dlnm () package in $\mathrm{R}$

$\mathrm{s}()$ : smoothing function of independent variables

$\mathrm{k}$ : limitation of degree of freedom in smoothing function factor(): indicator of categorical independent variables air pollutants: $\operatorname{LogPM} \mathrm{PM}_{10}, \mathrm{SO}_{2}, \mathrm{NO}_{2}$ and/or $\mathrm{O}_{3}$

DOS: day of study $(1,2,3, \ldots, 2922)$

DOY: day of year $(1,2,3, \ldots, 365 / 366)$

DOW: day of week $(1,2,3, \ldots, 7)$

Meteorological variables and air-pollutant variables were modelled simultaneously using DLNM. Same day rainfall, longterm time trend and day of year were modelled using natural 
Table 2 Cumulative RR from DLNMs describing associations between asthma hospitalisations and mean daily temperature by age group and season, Hong Kong, 2004-2011

\begin{tabular}{|c|c|c|c|c|c|c|c|c|c|c|}
\hline \multirow[b]{2}{*}{ Age group } & \multicolumn{5}{|c|}{ Hot season $(n=1232)$} & \multicolumn{5}{|c|}{ Cold season $(n=1180)$} \\
\hline & Ref. temp. ${ }^{*}\left({ }^{\circ} \mathrm{C}\right)$ & High temp.t $\left({ }^{\circ} \mathrm{C}\right)$ & Lag (day) & Cum. RR & $95 \% \mathrm{Cl}$ & Ref. temp. ${ }^{*}\left({ }^{\circ} \mathrm{C}\right)$ & Low temp.t $\left({ }^{\circ} \mathrm{C}\right)$ & Lag (day) & Cum. RR & $95 \% \mathrm{Cl}$ \\
\hline All & 27 & 30 & $0-3$ & 1.19 & 1.06 to 1.34 & 25 & 12 & $0-3$ & 1.33 & 1.13 to 1.58 \\
\hline Children $(<5)$ & 27 & 30 & $0-3$ & 1.08 & 0.82 to 1.43 & 25 & 12 & 0 & 1.10 & 0.88 to 1.38 \\
\hline Children (5-14) & 27 & 30 & $0-3$ & 1.32 & 1.01 to 1.74 & 25 & 12 & $0-2$ & 1.77 & 1.15 to 2.73 \\
\hline Adults (15-59) & 26 & 30 & $0-12$ & 1.52 & 1.13 to 2.06 & 25 & 12 & $0-3$ & 1.77 & 1.30 to 2.41 \\
\hline Older adults $(>59)$ & 28 & 30 & $0-3$ & 1.17 & 1.03 to 1.33 & 21 & 12 & $0-10$ & 1.67 & 1.25 to 2.22 \\
\hline
\end{tabular}

*Reference value used for comparison with extreme values was (1) the 97th percentile of the season for monotonic association or (2) the value associated with the lowest risk of admissions for U-shaped association or (3) the threshold value.

tExtreme values were the 3 rd percentile or the 97 th percentile during seasons.

DLNM, distributed lag nonlinear model; RR, relative risk; Temp., mean temperature.

cubic splines while holiday and day of week were adjusted as categorical factors. Mean wind speed and total rainfall were square root transformed and $\mathrm{PM}_{10}$ was log transformed to reduce skewness and the influence of outliers. Since influenza and acute respiratory infections (ARIs) were associated with exacerbation of asthma, the daily numbers of hospitalisations of influenza and ARIs were included as predictors in models during model selection. As air pollutants are usually highly correlated with each other, single-pollutant and multi-pollutant models were built and compared to reveal the independent associations between air pollutants and asthma admissions.

Maximum lags of 20-30 days have been commonly used in modelling temperature due to the relatively longer observed lagged effect of cold temperature, ${ }^{2} 71819$ while lagged effect of air pollutants are usually shorter. ${ }^{20}$ Maximum lags for DLNMs were chosen by comparing relative risk (RR)-lag associations generated from initial DLNMs using different maximum lags (10-30 days). The shortest maximum lag that could capture a robust lagged effect was chosen. The number of degrees of freedom (df) for variable terms was chosen by minimising the generalised cross validation (GCV) score in the $\operatorname{mgcv}()$ package $^{17}$ in $\mathrm{R}$. The most common df adapted for seasonal trend per year was 7 in similar studies. ${ }^{21}$ Data were split into half for seasonal analyses in this study, therefore the $\mathrm{df}$ was adjusted accordingly and a df of 5 was used. The reference values for environmental variables used for comparison with extreme values (the $3 \mathrm{rd}$ and the 97 th percentile) depended on the nature of the association identified. The $3 \mathrm{rd} / 50$ th/97th percentile of the variable, the value that was associated with the minimum risk of admissions and the threshold point were used for monotonic association, U-shaped association and when a threshold point was observed, respectively.

To better illustrate the changes in estimated risk of asthma admissions (in \%) among the overall population per unit change in environmental factors, factors that showed linear or partially linear associations with asthma admissions in the initial DLNM were put into piecewise linear models. Thresholds for the piecewise terms were using a grid search of reasonable values chosen by visual examination of DLNM plots. Thresholds used in the final piecewise models were those that minimised the GCV score while the length of lagged effects considered were chosen with reference to the results from the DLNMs.

Separate analyses were performed for the hot season (MayOctober) and the cold season (November-April). Season has been reported as a possible effect modifier on the association between environmental factors and respiratory morbidity in a previous local study, ${ }^{22}$ therefore the same classification of season was adopted for this study. Subgroup analyses by age group were done for older adults (aged 60 or over), working age adults (aged 15-59) and children (aged under 15). Children were further grouped into young children (under 5) and children aged 5-14. The length of lagged effects for different age groups was assessed using plots of single day and cumulative RRs versus lag days and observing the length of time that lagged effects persisted. If the RR was observed to be elevated for up to $\mathrm{k}$ days then the cumulative RR for $0-\mathrm{k}$ days was reported.

\section{Model checking and sensitivity analyses}

Residual plots and partial autocorrelation (PACF) plots of residuals were used for assessing the appropriateness of models and

Table 3 Cumulative RR from DLNM describing associations between asthma hospitalisations and daily mean RH by age group and season, Hong Kong, 2004-2011

\begin{tabular}{|c|c|c|c|c|c|c|c|c|c|c|}
\hline \multirow[b]{2}{*}{ Age group } & \multicolumn{5}{|c|}{ Hot season $(n=1232)$} & \multicolumn{5}{|c|}{ Cold season $(n=1180)$} \\
\hline & Ref. $\mathbf{R H}^{*}(\%)$ & High RH† (\%) & Lag (day) & Cum. RR & $95 \% \mathrm{Cl}$ & Ref. $\mathbf{R H}^{*}(\%)$ & Low RH† (\%) & Lag (day) & Cum. RR & $95 \% \mathrm{Cl}$ \\
\hline All & 70 & 94 & $0-12$ & 1.13 & 0.83 to 1.54 & 83 & 49 & $0-12$ & 1.19 & 0.99 to 1.43 \\
\hline Children $(<5)$ & 70 & 94 & $0-3$ & 1.46 & 0.93 to 2.28 & 83 & 49 & $0-5$ & 0.91 & 0.64 to 1.29 \\
\hline Children (5-14) & 70 & 94 & $0-12$ & 4.31 & 1.86 to 9.96 & 83 & 49 & 0-10 & 0.96 & 0.59 to 1.55 \\
\hline Adults (15-59) & 83 & 94 & $0-10$ & 1.28 & 0.78 to 2.12 & 83 & 49 & $0-10$ & 1.56 & 1.14 to 2.15 \\
\hline Older adults (above 59) & 80 & 94 & $0-10$ & 1.08 & 0.71 to 1.66 & 83 & 49 & $0-25$ & 1.26 & 0.87 to 1.83 \\
\hline
\end{tabular}

* Reference value used for comparison with extreme values was (1) the median of the season for monotonic association or (2) the value associated with the lowest risk of admissions for U-shaped association or (3) the threshold value.

tExtreme values were the 3rd percentile or the 97th percentile during seasons.

DLNM, distributed lag nonlinear model; RH, relative humidity; RR, relative risk. 
partial autocorrelation of residuals. Any time-related potential confounders that were not included in the models would cause autocorrelation in residuals, which in turn would cause bias in the SE estimates. To minimise autocorrelations, autoregressive terms were added to the models for the lags with a value of PACF higher than 0.1 in the first 30 days. Sensitivity analyses were done by applying different $\mathrm{df}$ for the lag terms to the models to observe the robustness of the results. All statistical analyses were done using R V.3.0.3.

\section{RESULTS}

There were a total of 56112 asthma admissions during the 8 -year study period. Among these, 33.07\%, 27.60\% and $39.38 \%$ were in children, adults and older adults, respectively. The average daily numbers of admissions were 19.20, 17.45 and 20.89 for the whole year, hot season and cold season, respectively. Daily mean temperatures ranged from $8.8^{\circ} \mathrm{C}$ to $31.8^{\circ} \mathrm{C}$. The median daily mean temperatures $(3 \mathrm{rd}, 97 \mathrm{th}$ percentile) were $24.6^{\circ} \mathrm{C}\left(12.7^{\circ} \mathrm{C}, 30.0^{\circ} \mathrm{C}\right), 27.8^{\circ} \mathrm{C}\left(23.6^{\circ} \mathrm{C}, 30.4^{\circ} \mathrm{C}\right)$ and $19.3^{\circ} \mathrm{C}\left(11.7^{\circ} \mathrm{C}, 25.9^{\circ} \mathrm{C}\right)$ for the whole year, hot and cold seasons, respectively. Descriptive statistics for overall asthma hospitalisations and environmental variables during the study period by season are shown in table 1 .

Maximum lags of 30 and 15 days with df of 4 were used for the lag parameter for temperature/RH and other environmental factors in DLNMs, respectively. $\mathrm{A} \mathrm{df}=4$ or 3 for meteorological variables, and $\mathrm{df}=2$ for pollutant variables was chosen for use in the variable parameter in final DLNMs.

\section{Hot season regression analyses}

For the overall population, the minimum morbidity temperature (MMT) was about $27^{\circ} \mathrm{C}$. The RR for asthma admissions increased when the mean temperature rose from $27^{\circ} \mathrm{C}$ to about $30^{\circ} \mathrm{C}$ and then plateaued for a temperature higher than $30^{\circ} \mathrm{C}$ (figure 1). The wide 95\% CI of RR for temperature higher than $30^{\circ} \mathrm{C}$ suggested the association was not significant and was less conclusive in this temperature range, possibly caused by the small number of days with mean temperature higher than $30^{\circ} \mathrm{C}$ during the study period (about 6\% of hot season days). The lagged effect lasted for about 3 days and the cumulative (cum.) $\mathrm{RR}$ for high temperatures $\left(\operatorname{lag} 0-3,30^{\circ} \mathrm{C}\right.$ vs $\left.27^{\circ} \mathrm{C}\right)$ was 1.19 (95\% CI 1.06 to 1.34) (table 2). In the piecewise linear model, the estimated risk increase per $1^{\circ}$ increase in mean temperature (lag $0-3$ days) for a mean temperature above $27.9^{\circ} \mathrm{C}$ was $6.00 \%$ (95\% CI $1.60 \%$ to $10.58 \%$; $\mathrm{p}=0.007)$. Asthma risk increased when RH increased from $70 \%$ to about $87 \%$ and then stopped increasing for higher RH. However, the wide CI suggested that the association was less conclusive for RH higher than $90 \%$. Cum. RR for high RH (lag0-12, 94\% vs 70\%) was $1.13(95 \%$ CI 0.83 to 1.54 ) (table 3). Every $1 \%$ increase in RH (lag $0-12$ days) was associated with a $1.89 \%(95 \% \mathrm{CI}-0.02 \%$ to $3.83 \%$; $\mathrm{p}=0.052$ ) increase in estimated risk for RH above $82 \%$ in the piecewise model. Solar radiation demonstrated a negative association with asthma admissions with a cum. RR for low solar radiation $\left(\operatorname{lag} 0-7,3\right.$ vs $\left.15.88 \mathrm{MJ} / \mathrm{m}^{2}\right)$ of $1.26(95 \%$ CI 0.91 to 1.74). A $1 \mathrm{MJ} / \mathrm{m}^{2}$ decrease in solar radiation was associated with a $2.06 \%(95 \%$ CI $3.02 \%$ to $1.08 \%$; $\mathrm{p}<0.0005)$ change in estimated risk in the piecewise model. High wind speed was associated with fewer asthma admissions but the association was not significant. Concentration of ozone showed a strong positive association with asthma admissions in single-pollutant and multi-pollutant models. The cum. RRs for high level of ozone ( $\operatorname{lag} 0-3$, 97th percentile of $78 \mu \mathrm{g} / \mathrm{m}^{3}$ vs median of $26.62 \mu \mathrm{g} / \mathrm{m}^{3}$ ) in the single-pollutant model and the multi-pollutant model

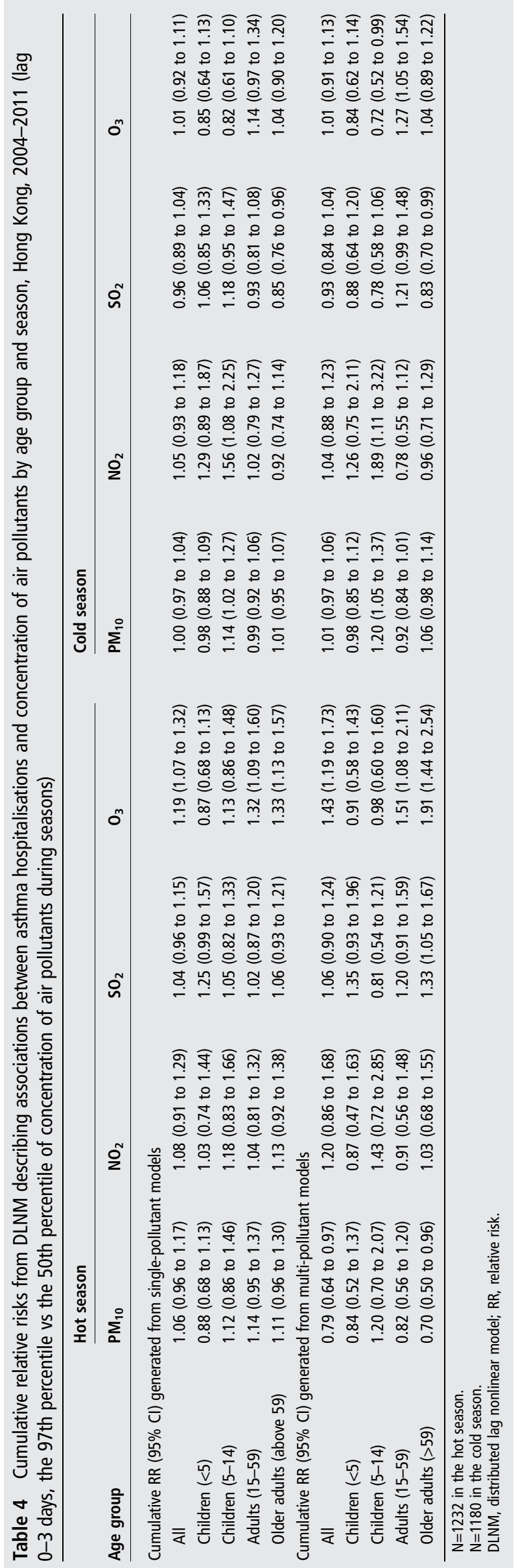



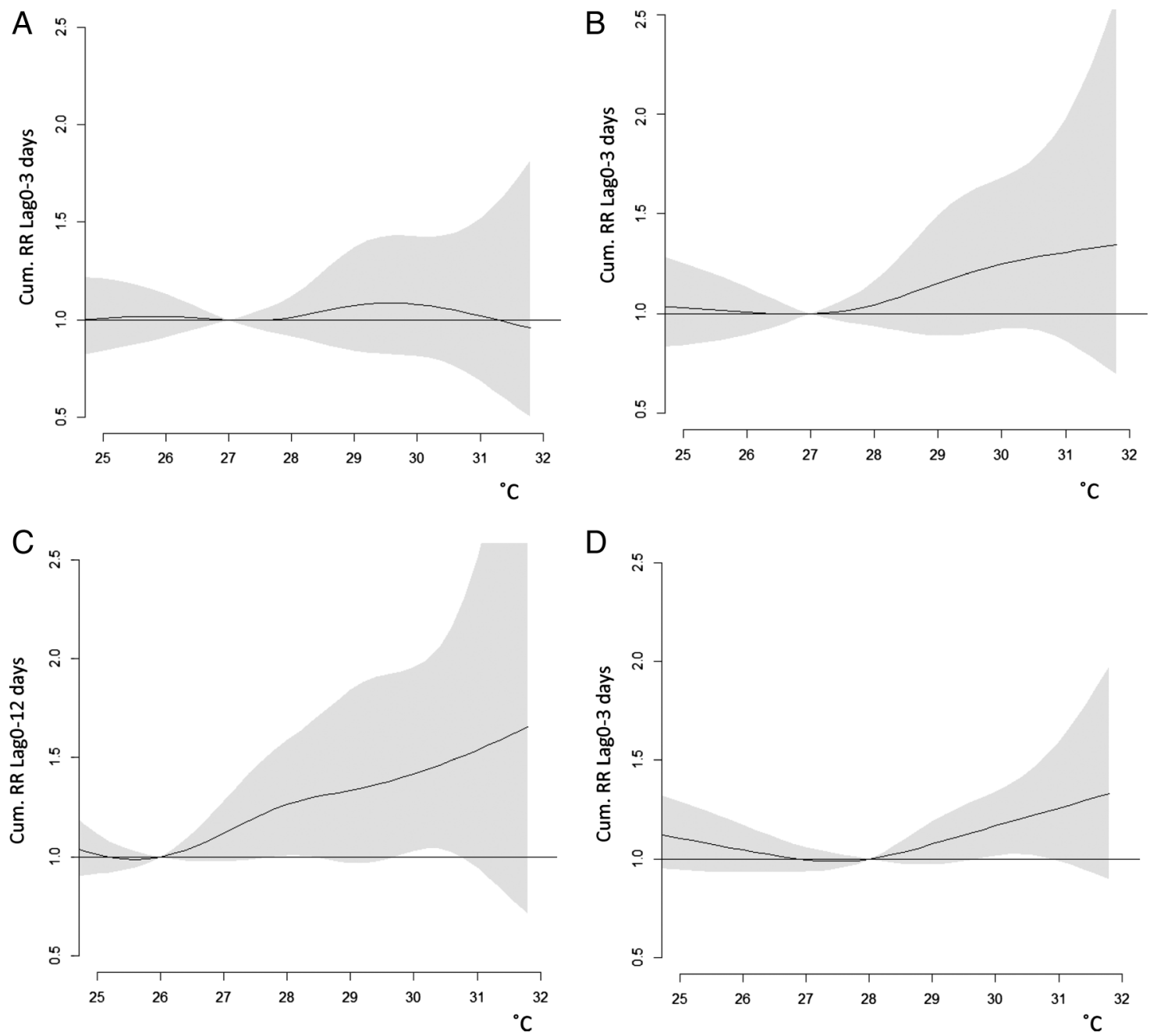

Figure 2 Plots of cumulative relative risks (cum. RR) against mean temperature during the hot season (May-0ctober, 2004-2011, Hong Kong) among patients with asthma by age group: (A) under 5, (B) 5-14, (C) 15-59 and (D) 60+.

were 1.19 (95\% CI 1.07 to 1.32 ) and 1.44 (95\% CI 1.19 to $1.73)$, respectively. Every $10 \mu \mathrm{g} / \mathrm{m}^{3}$ increase in ozone was associated with a $4.04 \%(95 \%$ CI $2.24 \%$ to $5.85 \%$; $<<0.0005)$ and $8.72 \%$ (95\% CI $5.31 \%$ to $12.15 \%$; $\mathrm{p}<0.0005$ ) increase in estimated risk in the piecewise single-pollutant and multi-pollutant models, respectively. No significant and consistent associations were observed for the other air pollutants (table 4).

Subgroup analyses by age group

While more asthma admissions were associated with higher temperatures and higher $\mathrm{RH}$ in all age groups, these associations were stronger for adults and older children than for young children and older adults. Adults also had a lower MMT at $26^{\circ} \mathrm{C}$ than either of the children's group, $27^{\circ} \mathrm{C}$, or older adults, $28^{\circ} \mathrm{C}$ (figure 2). Overall admissions among adults and older children were most sensitive to high temperature while the association among young children was the weakest and was not significant. The association between $\mathrm{RH}$ and admissions among children groups was $\mathrm{U}$ shaped with minimum risk at $70 \%$, while admissions among adults increased with high $\mathrm{RH}$ when $\mathrm{RH}$ rose over $83 \%$ (figure 3). The associations were strongest in older children, followed by adults, young children and then older adults. Wind speed and solar radiation did not show significant associations for any age group, while ozone demonstrated a strong and positive association with asthma admissions among adults and older adults in single-pollutant and multi-pollutant models (table 4). Adult admissions were most sensitive to environmental factors, while those in young children under 5 were least sensitive. A residual seasonal pattern, demonstrated by plotting the smooth term for day of year, was observed for all age groups, with admissions bottoming out from mid-July to mid-August, with a sharper drop for children (figure 4).

\section{Cold season regression analyses}

For the overall population, asthma hospitalisations were negatively associated with ambient mean temperature, with lagged effects lasting about 3 days. The cum. RR for low temperature $\left(\operatorname{lag} 0-3,12^{\circ} \mathrm{C}\right.$ vs $25^{\circ} \mathrm{C}$ ) was $1.33(95 \%$ CI 1.13 to 1.58$)$ (table 2). For temperatures below $15.2^{\circ} \mathrm{C}$, a $1^{\circ}$ drop in mean temperature was associated with $5.79 \%$ (95\% CI $3.29 \%$ to $8.36 \%$; $\mathrm{p}=0.012$ ) increase in estimated risk in the piecewise model. RH was negatively associated with asthma admissions (figure 5). The RR for low RH (lag0-12, 49\% vs 83\%) was 1.19 (95\% CI 0.99 to 1.43 ) (table 3). Every 1\% drop in RH below 58\% was associated with a $2.88 \%$ (95\% CI $0.37 \%$ to $5.45 \%$; $=0.024$ ) increase in estimated risk in the piecewise model. High solar radiation and low wind speed were associated with more admissions but the associations were not significant (figure 5). None of the studied air pollutants showed consistent and significant associations with asthma admissions in the cold season (table 4). 

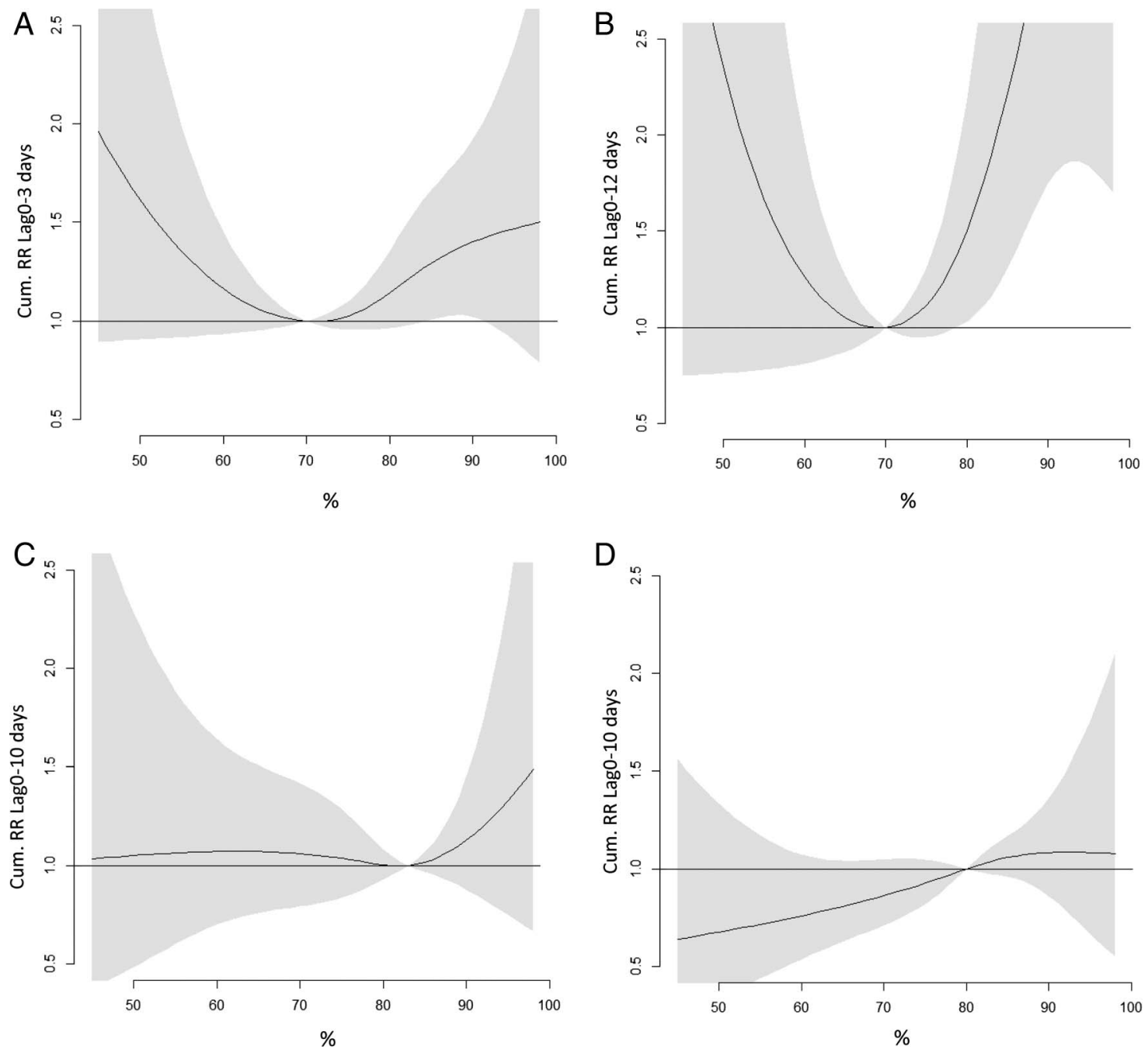

Figure 3 Plots of cumulative relative risks (cum. RR) against mean relative humidity during the hot season (May-0ctober, 2004-2011, Hong Kong) among patients with asthma by age group: (A) under 5, (B) 5-14, (C) 15-59 and (D) 60+.

Subgroup analyses by age group

Admissions increased when temperatures dropped below about $20^{\circ} \mathrm{C}$ for older children, adults and older adults, while those among young children increased when mean temperature dropped from the seasonal maximum of $27.8^{\circ} \mathrm{C}$ to $20^{\circ} \mathrm{C}$, then declined for lower temperatures, though the association was not significant (figure 6). The association with low temperatures was strongest among adults and older children, followed by older adults. Low $\mathrm{RH}$ was associated with more admissions among adults and older adults but not in children (figure 7). The association was negative throughout the $\mathrm{RH}$ range in adults and was $\mathrm{U}$ shaped among older adults when RH was higher than $60 \%$, with a minimum morbidity $\mathrm{RH}$ at $83 \%$. Wind speed and solar radiation did not show significant associations for any age group. $\mathrm{PM}_{10}$ and $\mathrm{NO}_{2}$ were significantly and positively associated with number of admissions in older children in singlepollutant and multi-pollutant models (table 4). No significant, positive and consistent associations with any air pollutants were observed in other subgroups. Overall, adult admissions were most sensitive, and young children's admissions were least sensitive, to temperature variation. A residual seasonal pattern was observed for both children's groups, with admissions increasing from January to April (figure 8).

\section{DISCUSSION}

Our study found that associations between asthma admissions and environmental factors varied by season and age group. Adults were most sensitive to temperature and RH while children under 5 years old were least sensitive to environmental factors. Asthma admissions increased at high temperatures in the hot season and at low temperatures in the cold season. The nature of associations reported from past studies of asthma morbidity and temperatures have not been consistent, likely due to differences in climate, study design and statistical methodology. Some studies have found positive associations between temperatures and asthma admissions, ${ }^{23} 24$ some have reported negative associations, ${ }^{2} 57816192526$ while a few have reported significant associations with high and low temperatures. ${ }^{6} 27$ The seasonal differences in associations of $\mathrm{RH}$ with asthma hospitalisations observed in this study, negative association in the cold season and positive in the hot season, have not been commonly reported in previous studies. Among the limited number of studies examining the associations between asthma hospitalisations and RH, two US studies reported positive associations with RH but negative associations with temperature. ${ }^{25}$ However, neither study performed stratified analyses by season and they both assessed only linear associations. ${ }^{9} 25$ 

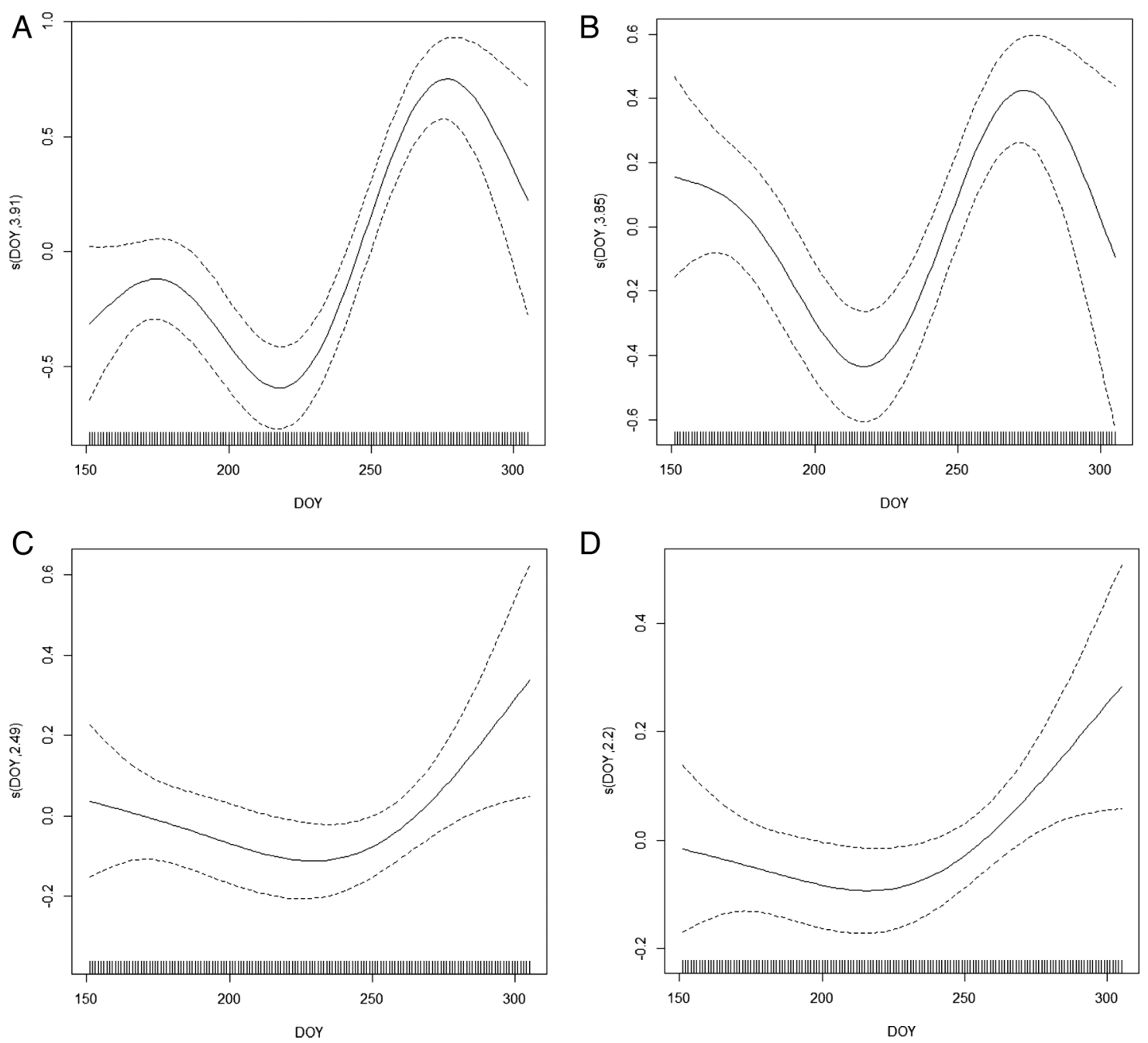

Figure 4 Plots of residual seasonal trend (smooth term of DOY) against day of year during the hot season (May-0ctober, 2004-2011, Hong Kong) among patients with asthma by age group: (A) under 5, (B) 5-14, (C) $15-59$ and (D) $60+$.

Among pollutants, ozone demonstrated the strongest positive association with asthma admissions (only in the hot season) in our study. Positive asthma-ozone associations have been reported in other studies ${ }^{20}{ }^{28-32}$ and previous Hong Kong studies also reported significant associations between increased asthma admissions and ozone in multi-pollutant models. ${ }^{20} 3334$ Studies from London, the USA and Turkey have also reported that ozone was positively associated with asthma only in the hot season. ${ }^{30}$ 35-38 Previous reports have suggested that the complicated mixture of air pollutants, the possibly higher exposure to air pollutants due to the longer time spent outdoors in the hot season, or some as yet unknown synergism between high temperature and ozone might contribute to the stronger association observed between asthma conditions and ozone in the hot season. ${ }^{30} 3637$ While in our data mean $\mathrm{O}_{3}$ concentrations were higher in the cold season, there were more days with very high $\mathrm{O}_{3}$ in the hot season.

Our study found that although the risk of asthma exacerbations increased at high and low temperatures and that the association with low temperatures was stronger. Previous studies have reported the association of low temperatures with decreasing lung function, higher risk of airway inflammation and lower lung capacity. ${ }^{39}$ Together with low temperatures, low humidity, which can induce bronchoconstriction and dry the mucosal membrane along the airway, also increases the risk of asthma exacerbations. Cold and dry air decreases the humidity of the mucosal membrane and hence increases susceptibility to airway bacterial and viral infections and irritation by allergens and other irritants. ${ }^{4142}$ Low temperatures and low levels of humidity also favour the survival of viruses like influenza and respiratory syncytial virus ${ }^{43}$ which will also increase the risk of infection-induced triggers. The observed effect modification by season of the associations between asthma admissions and temperature is likely due to a U-shaped association between temperature and asthma which is reflected in a positive association in the summer, when temperatures range from moderate to hot, and a negative association in the winter, when temperatures range from moderate to cold. The effect modification of the association between $\mathrm{RH}$ and asthma by season may reflect a temperature- $\mathrm{RH}$ interaction as high $\mathrm{RH}$ can exacerbate heat stress during periods of high temperatures, while low RH may be linked with asthma during periods of cold temperature for reasons discussed above.

In addition, neutrophils might also play important roles in temperature-related triggers. The cell is a kind of biomarker of asthma exacerbations. ${ }^{44}$ High neutrophil counts are commonly seen in sputum and bronchial lavage of patients with chronic severe asthma (in infection-related exacerbations and non-infection-related exacerbations) while this was less likely to be observed in patients with mild and moderate asthma. ${ }^{44}$ 

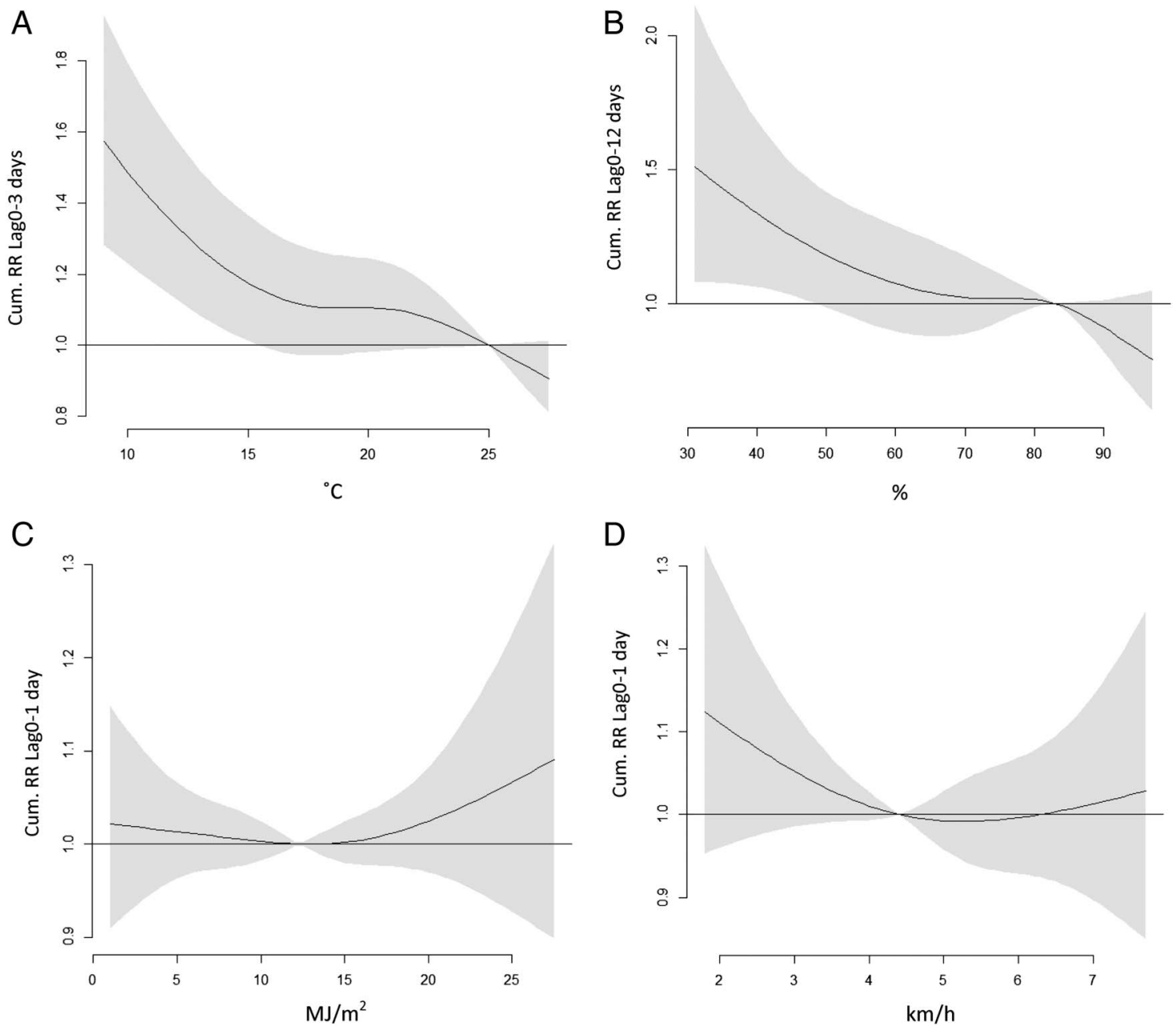

Figure 5 Plots of cumulative relative risks (cum. RR) during the cold season (November-April, 2004-2011, Hong Kong) in overall population against: (A) mean temperature, (B) relative humidity, (C) solar radiation, (D) square-root-transformed wind speed.

Previous studies have reported ambient temperature, especially low temperatures, have significant effects on suppressing the immune system. ${ }^{45} 46$ Low temperatures induce secretion of corticosteroid which increases the level of neutrophils. ${ }^{44} 45$ Neutrophils release mediators that cause bronchial epithelial damage and airway obstruction. ${ }^{44}$ This may be associated with the acute exacerbations among patients with severe asthma when the neutrophil count rises due to the increasing level of corticosteroid in low temperatures. ${ }^{44} 45$ Thus, the contributions of neutrophils may partly explain the strong association between low temperatures and asthma hospitalisations. Some studies also suggested that high temperatures have a similar effect on level of corticosteroid but the findings were less conclusive in humans. ${ }^{46}$ Our result also showed that older age groups were more sensitive to low temperatures. Since high neutrophil counts have been observed more commonly in chronic severe asthma cases than in mild and moderate asthma, older patients with asthma with a longer history of asthma may be more vulnerable to changing neutrophil levels induced by extreme temperatures.

Despite the fact that many previous studies have reported associations between high temperatures and asthma morbidity, ${ }^{6} 232427$ the direct biological mechanisms by which high temperatures cause asthma exacerbations are still unclear. A recent study suggested that the pulmonary c-fibre sensory nerve plays an important role in asthma in hot temperatures. ${ }^{47}$ High temperatures may activate the c-fibre nerve and enhance bronchoconstrictions. ${ }^{47}$ Another possible link between high temperatures, high humidity and asthma is the amount of airborne allergens. High temperatures and high $\mathrm{RH}$ favour production of many airborne allergens such as tree pollens and fungal spores. ${ }^{48}$ Moulds are more likely to grow in damp places while mites are at higher concentrations in high humidity. ${ }^{49}$ High temperatures also favour the production of ozone through photolysis. The higher concentrations of allergens and air pollutants in the air may increase the stimulus to the hyperreactive airway and aggravate airway inflammation in people with asthma. High wind speeds, which enhance dispersion of air pollutants and allergens, may lower the number of admissions by reducing exposure to irritants.

In subgroup analysis by age, adult admissions were most sensitive to both ambient temperatures and RH while young children's admissions were least sensitive to environmental factors. This is consistent with the results of previous studies from Taiwan and Japan that stronger associations were found between ambient temperatures and asthma admissions among adults compared with the elderly (age $>65$ years) and children (age $<15$ years), respectively. ${ }^{8} 16$ Although the Korean study reported a stronger association between asthma admissions and low temperatures among children $(<15)$ than in the older age groups, ${ }^{5}$ the study did not compare associations between young children $(<5)$ and older children (5-14). A study reported 

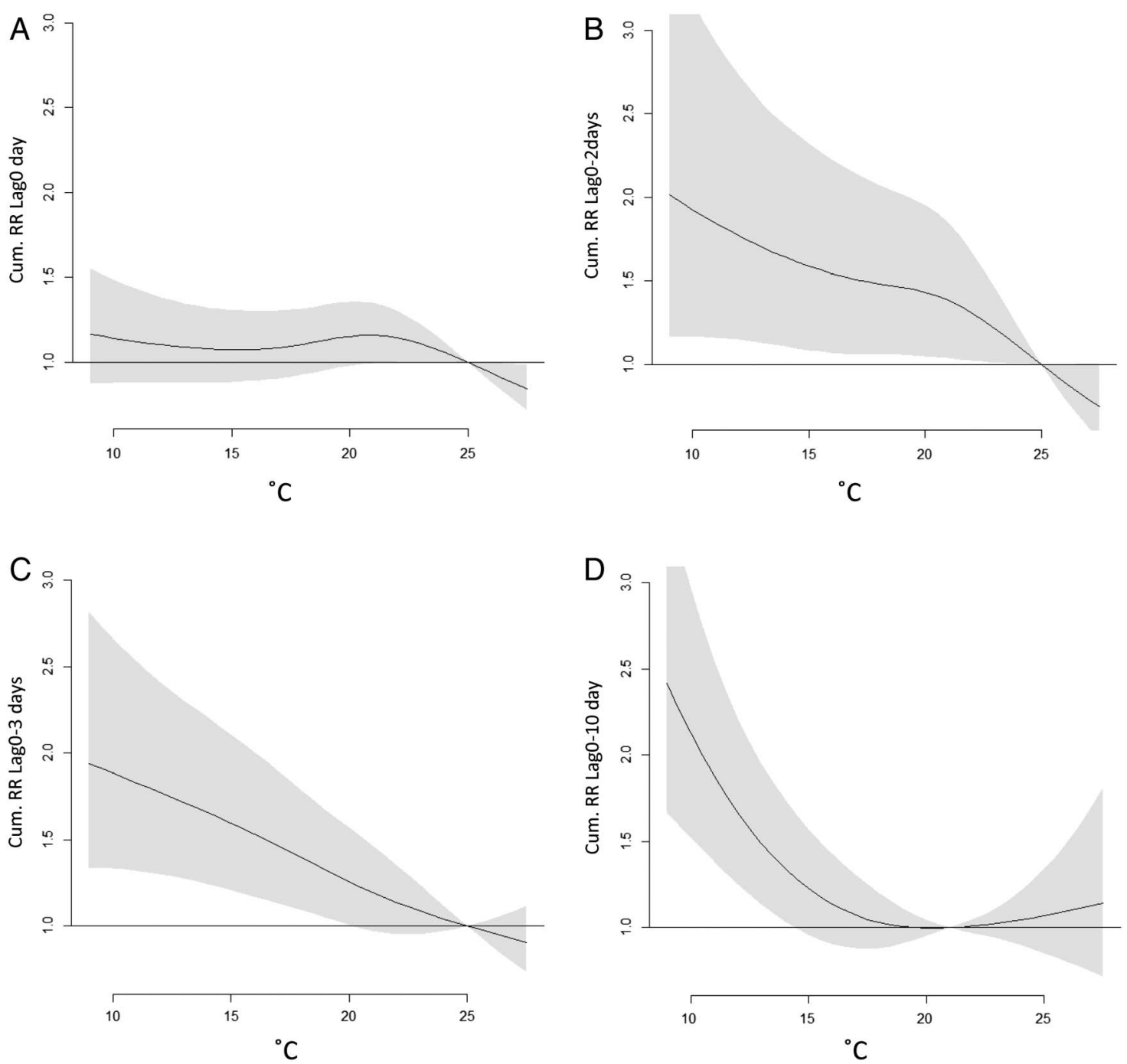

Figure 6 Plots of cumulative relative risks (cum. RR) against mean temperatures during the cold season (November-April, 2004-2011, Hong Kong) among patients with asthma by age group: (A) under 5, (B) 5-14, (C) 15-59 and (D) 60+.

adults with severe asthma tended to have more severe airway obstruction and tended to have poorer responsiveness to glococorticoids than children with asthma. ${ }^{12}$ This might be related to higher prevalence of smoking, longer duration of airway inflammation and the lower lung function in adults compared with children. ${ }^{12}$ Moreover, adults are the major working population and likely have more active social lives than children or older adults. This might increase their exposure to environmental triggers as they are less able to avoid going out during periods of unfavourable environmental conditions.

Asthma admissions among young children (below 5) did not show significant associations with environmental factors. A possible reason for these weak associations is that pre-school-aged children generally spend more time indoors, and their lifestyle and activities are usually restricted by parents. In addition, children, particularly younger children, are more likely to have their compliance with their medication regimens monitored and reinforced, whereas compliance among adolescents and adults may be more lax. Thus older groups may be more likely to have residual airway inflammation due to poorer compliance and therefore be more susceptible to environmental triggers.

A significant $\mathrm{V}$-shaped seasonal pattern in the hot season was observed among the two children's groups both before and after environmental variables were adjusted, with hospitalisations declining from May to a minimum risk point during mid-August, then rising again through September and October. This is possibly due to changes in exposure to infectious pathogens during the school summer holiday. The crowded environment in schools likely enhances the spread of infectious pathogens between students, increasing the risk of respiratory infections and related triggers among children with asthma. This may explain the changing risks during school term and the summer break. The seasonal trends in adults and the elderly were similar but were less significant after environmental factors were adjusted.

A strength of this study was the use of a comprehensive and reliable database which was systematically maintained by the Hospital Authority of Hong Kong. The dataset includes more than $83 \%$ of total hospital admissions in Hong Kong over an 8 -year study period $^{22}$ in 2922 days, which provided the study with credible precision and power. ${ }^{21}$ The use of a combination of GAM and DLNM also provided flexibility for modelling the potentially nonlinear and lagged association between environmental variables and asthma hospitalisations. Moreover, this study was one of the few studies that compared associations between asthma admissions and ambient temperature among different age groups within the same population. 

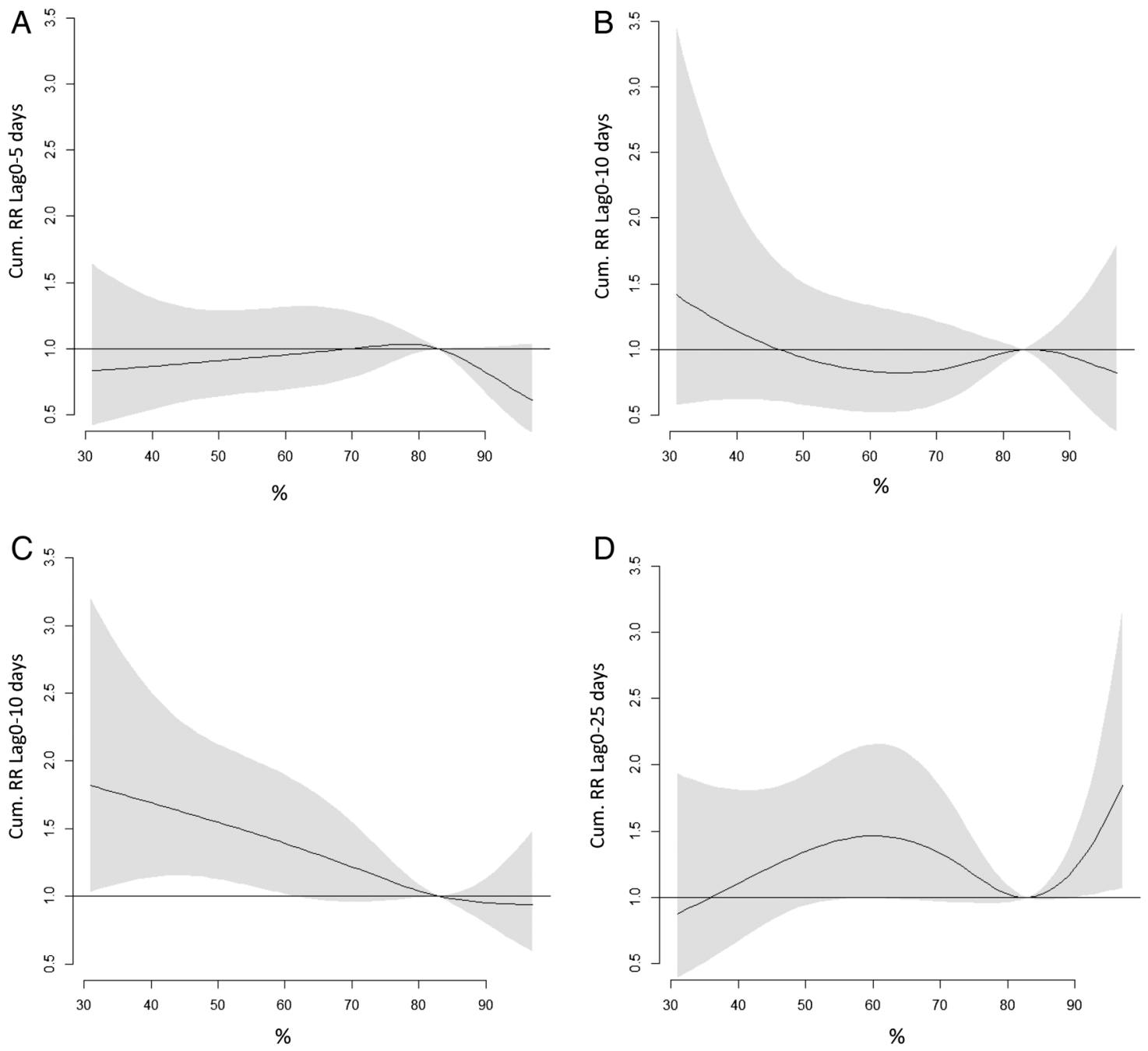

Figure 7 Plots of cumulative relative risks (cum. RR) against mean relative humidity during the cold season (November-April, 2004-2011, Hong Kong) among patients with asthma by age group: (A) under 5, (B) 5-14, (C) 15-59 and (D) 60+.

Major limitations of this study were the assumption of the same levels of exposure and direct exposure to environmental factors for the whole population. However, exposures vary among people with different occupations and from different socioeconomic classes due to differences in the amount of time spent outdoors and the use of air conditioning, heating and humidifiers. Lack of spatial data is another limitation in this study. While there are several other weather stations around Hong Kong, the data reported from the central HKO weather station is the most complete in terms of the number of variables collected and having no missing data. Hong Kong is small geographically, despite its large population, and the HKO site is located close to the densely populated areas of Kowloon and Northern Hong Kong Island. In addition, the correlation between the various weather stations for temperature was very high (0.99 in most cases) and is also high for RH\% (mostly $>0.92$ ). Therefore the data collected from the HKO site should accurately reflect meteorological conditions and their variations in Hong Kong. Furthermore, use of a single monitoring station for weather variables is standard for this sort of study done in urban areas, ${ }^{50}$ and a study on the use of multiple measuring stations in a densely populated European city ${ }^{50}$ found that there was 'no added value in taking into account data from multiple weather stations when estimating exposure in the Paris area'. Another potential limitation is that our data included some nonemergency hospital admissions. In general, non-emergency admissions are less likely to be in response to symptoms, and thus would be relatively insensitive to environmental factors. However, the percentage of such admissions was relatively small, $19 \%$ with reference to a previous local study, ${ }^{11}$ and some non-emergency admissions may also result from physician-noted symptom exacerbations. Therefore, we think it is unlikely that this issue will seriously affect our results. The inclusion of multiple environmental factors in the models, along with the fact that several subgroup analyses were conducted, raises the issue of multiple testing. We do not make any formal adjustment of the $\mathrm{p}$ values, but readers should keep this issue in mind. Lack of data on common asthma-related allergens like pollen is another limitation. The negative association between higher wind speed and asthma admissions likely partly results from the wind's role in dispersing these allergens. In addition, general practitioner consultations and emergency department visits that did not result in public hospital admissions during the study period were not included in the study. Thus we can view our study as examining meteorological associations with the incidence of more severe cases of asthma requiring hospitalisation. 

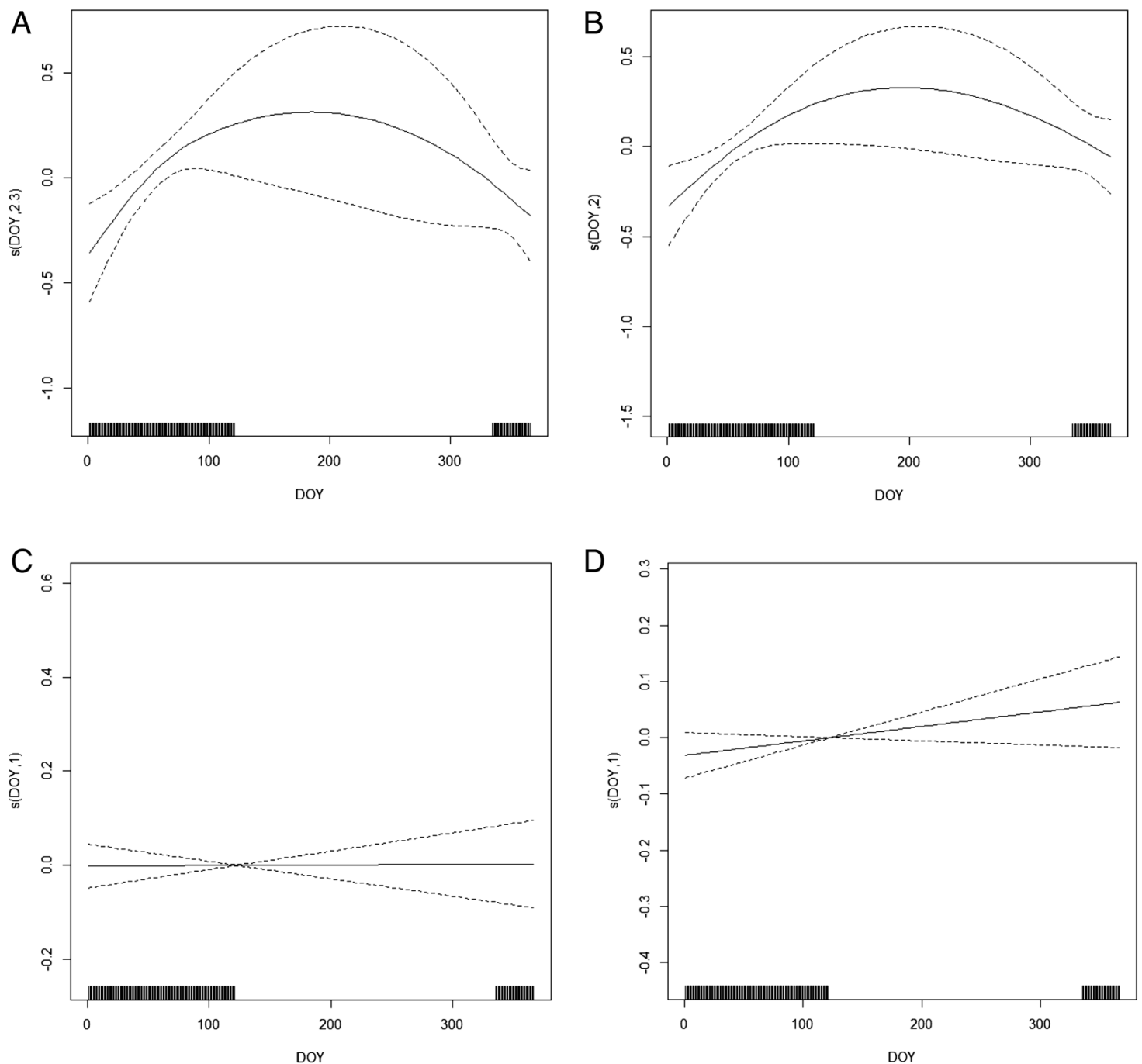

Figure 8 Plots of residual seasonal trend (smooth term of DOY) against day of year during the cold season (November-April, 2004-2011, Hong Kong) among patients with asthma by age group: (A) under 5, (B) 5-14, (C) $15-59$ and (D) $60+$.

\section{CONCLUSION}

Taking steps to reduce time outdoors during periods of adverse environmental conditions and the use of humidifiers/dehumidifiers and air conditioning to keep the optimum indoor temperatures and RH are recommended for people with asthma. The results of this study should be considered when reviewing targeted health precaution guidelines for patients with asthma in regards to extreme environmental conditions and should be referenced when forecasting resources in the healthcare systems in Hong Kong.

Acknowledgements The authors would like to acknowledge the Hospital Authority of Hong Kong, Hong Kong Observatory and Environmental Protection Department in Hong Kong for providing the data for this study.

Contributors HC-yL, EY-yC and WBG made substantial contributions to the conception or design of the work, or the acquisition, analysis or interpretation of the data. HC-yL, AML and WBG contributed to drafting the work or revising it critically for important intellectual content. WBG was responsible for final approval of the version published.

Competing interests None declared.

Ethics approval Ethics approval has been granted by the Survey and Behavioural Research Ethics Committee, The Chinese University of Hong Kong.

Provenance and peer review Not commissioned; externally peer reviewed.

\section{REFERENCES}

1 World Health Organization. Asthma Fact sheet No 307. 2013. http://www.who.int/ mediacentre/factsheets/fs307/en/ (accessed 3 Feb 2016).

2 Guo Y, Jiang F, Peng L, et al. The association between cold spells and pediatric outpatient visits for asthma in Shanghai, China. PLOS ONE 2012;7:e42232.

3 Li S, Baker PJ, Jalaludin BB, et al. Are children's asthmatic symptoms related to ambient temperature? A panel study in Australia. Environ Res 2014;133:239-45.

4 Mireku N, Wang Y, Ager J, et al. Changes in weather and the effects on pediatric asthma exacerbations. Ann Allergy Asthma Immunol 2009:103:220-4.

5 Son JY, Bell ML, Lee JT. The impact of heat, cold, and heat waves on hospital admissions in eight cities in Korea. Int I Biometeorol 2014:58:1893-903.

$6 \mathrm{Xu} \mathrm{Z}$, Huang C, Hu W, et al. Extreme temperatures and emergency department admissions for childhood asthma in Brisbane, Australia. Occup Environ Med 2013;70:730-5.

7 Zhang $\mathrm{Y}$, Peng L, Kan $\mathrm{H}$, et al. Effects of meteorological factors on daily hospital admissions for asthma in adults: a time-series analysis. PLOS ONE 2014:9:e102475.

8 Wang YC, Lin YK. Temperature effects on outpatient visits of respiratory diseases, asthma, and chronic airway obstruction in Taiwan. Int J Biometeorol 2015;59:815-25.

9 Delamater PL, Finley AO, Banerjee $\mathrm{S}$. An analysis of asthma hospitalizations, air pollution, and weather conditions in Los Angeles County, California. Sci Total Environ 2012:425:110-18.

10 Babin SM, Burkom HS, Holtry RS, et al. Pediatric patient asthma-related emergency department visits and admissions in Washington, DC, from 2001-2004, and associations with air quality, socio-economic status and age group. Environ Health 2007;6:9.

11 Qiu H, Yu IT, Tse LA, et al. Greater temperature variation within a day associated with increased emergency hospital admissions for asthma. Sci Total Environ 2015;505:508-13. 
12 Jenkins HA, Cherniack R, Szefler SJ, et al. A comparison of the clinical characteristics of children and adults with severe asthma. Chest 2003;124:1318-24.

13 Son JY, Lee JT, Anderson GB, et al. The impact of heat waves on mortality in seven major cities in Korea. Environ Heal Presepect 2012;566:566-71.

14 Yang J, Liu HZ, Ou CQ, et al. Impact of heat wave in 2005 on mortality in Guangzhou, China. Biomed Environ Sci 2013:26:647-54.

15 Reed CE. The natural history of asthma. J Allergy Clin Immunol 2006;118:543-8; quiz 549-50.

16 Abe T, Tokuda $Y$, Ohde $S$, et al. The relationship of short-term air pollution and weather to ED visits for asthma in Japan. Am J Emerg Med 2009;27:153-9.

17 Simon NW. Generalized additive models: an introduction with R. London: Chapman \& Hall, 2006.

18 Armstrong B. Models for the relationship between ambient temperature and daily mortality. Epidemiology 2006;17:624-31.

19 Hajat $\mathrm{S}$, Haines A. Associations of cold temperatures with GP consultations for respiratory and cardiovascular disease amongst the elderly in London. Int $J$ Epidemiol 2002;31:825-30.

20 Ko FWS, Tam W, Wong TW, et al. Effects of air pollution on asthma hospitalization rates in different age groups in Hong Kong. Clin Exp Allergy 2007:37:1312-19.

21 Bhaskaran K, Gasparrini A, Hajat S, et al. Time series regression studies in environmental epidemiology. Int J Epidemiol 2013;42:1187-95.

22 Chan EYY, Goggins WB, Yue SK, et al. Hospital admissions as a function of temperature, other weather phenomena and pollution levels in an urban setting in China. Bull World Heal Organ 2013;91:576-84.

23 Lin S, Luo M, Walker RJ, et al. Extreme high temperatures and hospital admissions for respiratory and cardiovascular diseases. Epidemiology 2009;20:738-46.

24 Yamazaki S, Shima M, Yoda Y, et al. Association of ambient air pollution and meteorological factors with primary care visits at night due to asthma attack. Environ Health Prev Med 2013;18:401-6.

25 May L, Carim M, Yadav K. Adult asthma exacerbations and environmental triggers: a retrospective review of ED visits using an electronic medical record. Am J Emerg Med 2011:29:1074-82

26 Vaneckova P, Bambrick H. Cause-specific hospital admissions on hot days in Sydney, Australia. PLOS ONE 2013;8:e55459.

27 Buckley JP, Richardson DB. Seasonal modification of the association between temperature and adult emergency department visits for asthma: a case-crossover study. Environ Health 2012;11:55.

28 Gent JF, Triche EW, Holford TR, et al. Association of low-level ozone and fine particles with respiratory symptoms in children with asthma. J Am Med Assoc 2003;290:1859-67.

29 Sunyer J, Spix C, Quénel P, et al. Urban air pollution and emergency admissions for asthma in four European cities: the APHEA Project. Thorax 1997;52:760-5.

30 Altuğ H, Gaga EO, Döğeroğlu T, et al. Effects of air pollution on lung function and symptoms of asthma, rhinitis and eczema in primary school children. Environ Sci Pollut Res Int 2013;20:6455-67.

31 Silverman RA, Ito K. Age-related association of fine particles and ozone with severe acute asthma in New York City. J Allergy Clin Immunol 2010;125:367-73.e5.
32 Guarnieri M, Balmes JR. Outdoor air pollution and asthma. Lancet 2014:383:1581-92.

33 Wong TW, Lau TS, Yu TS, et al. Air pollution and hospital admissions for respiratory and cardiovascular diseases in Hong Kong. Occup Environ Med 1999;56:679-83.

34 Lee SL, Wong WH, Lau YL. Association between air pollution and asthma admission among children in Hong Kong. Clin Exp Allergy 2006;36:1138-46.

35 Delfino RJ, Wu J, Tjoa T, et al. Asthma morbidity and ambient air pollution: effect modification by residential traffic-related air pollution. Epidemiology 2014;25:48-57.

36 Strickland MJ, Darrow LA, Klein M, et al. Short-term associations between ambient air pollutants and pediatric asthma emergency department visits. Am J Respir Crit Care Med 2010;182:307-16.

37 Anderson HR, Ponce de Leon AP, Bland JM, et al. Air pollution, pollens, and daily admissions for asthma in London 1987-92. Thorax 1998;53:842-8.

38 Samoli E, Nastos PT, Paliatsos AG, et al. Acute effects of air pollution on pediatric asthma exacerbation: evidence of association and effect modification. Environ Res 2011;111:418-24.

39 Koskela $\mathrm{H}$, Pekkarinen $\mathrm{H}$, Kononoff $\mathrm{A}$. Effect of whole-body exposure to cold and wind on lung function in asthmatic patients. Chest 1994;105:1728-31.

40 Donaldson GC, Seemungal T, Jeffries DJ, et al. Effect of temperature on lung function and symptoms in chronic obstructive pulmonary disease. Eyr Resoir $J$ 1999:13:844-9.

41 Chan PKS, Mok HY, Lee TC, et al. Seasonal influenza activity in Hong Kong and its association with meteorological variations. J Med Virol 2009:81:1797-806.

42 Jaakkola K, Saukkoriipi A, Jokelainen J, et al. Decline in temperature and humidity increases the occurrence of influenza in cold climate. Environ Heal 2014;13:22.

43 Tang JW, Lai FYL, Wong F, et al. Incidence of common respiratory viral infections related to climate factors in hospitalized children in Hong Kong. Epidemiol Infect 2010;138:226-35.

44 Sampson AP. The role of eosinophils and neutrophils in inflammation. Clin Exp Allergy 2000;30(Suppl 1):22-7.

45 LaVoy ECP, McFarlin BK, Simpson RJ. Immune responses to exercising in a cold environment. Wilderness Environ Med 2011;22:343-51.

46 Mahima, Ingle AM, Verma AK, et al Immunomodulators in day to day life: a review. Pakistan J Biol Sci 2013;16:826-43.

47 Hayes D, Collins PB, Khosravi M, et al. Bronchoconstriction triggered by breathing hot humid air in patients with asthma: role of cholinergic reflex. Am J Respir Crit Care Med 2012;185:1190-6.

48 Tang JW. The effect of environmental parameters on the survival of airborne infectious agents. J $R$ Soc Interface 2009;6(Suppl 6):S737-46.

49 Forsberg $B$, Bråbäck L, Keune $H$, et al. An expert assessment on climate change and health-with a European focus on lungs and allergies. Environ Heal 2012;11 (Suppl 1):S4.

50 Schaeffer L, de Crouy-Chanel P, Wagner V, et al. How to estimate exposure when studying the temperature-mortality relationship? A case study of the Paris area. Int $J$ Biometeorol 2016;60:73-83. 